\title{
Elevated level of D-dimer increases the risk of stroke
}

Research Paper

\author{
Jing Zhang ${ }^{1, *}$, Yanlin Song ${ }^{2, *}$, Baoyin Shan ${ }^{1, *}$, Min He ${ }^{1}$, Qingqing Ren ${ }^{1}$, Yunhui Zeng ${ }^{1}$, \\ Zhiyong Liu ${ }^{1}$, Hao Liu ${ }^{1}$ and Jianguo $\mathrm{Xu}^{1}$ \\ ${ }^{1}$ Department of Neurosurgery, West China Hospital, Sichuan University, Chengdu 610041, PR China \\ ${ }^{2}$ West China School of Medicine, West China Hospital, Sichuan University, Chengdu 610041, PR China \\ *These authors have contributed equally to this work \\ Correspondence to: Jianguo XU, email: jianguo_1229@126.com \\ Keywords: D-dimer; stroke; risk factor \\ Received: August 05, $2017 \quad$ Accepted: September 20, $2017 \quad$ Published: December 18, 2017 \\ Copyright: Zhang et al. This is an open-access article distributed under the terms of the Creative Commons Attribution License 3.0 \\ (CC BY 3.0), which permits unrestricted use, distribution, and reproduction in any medium, provided the original author and source \\ are credited.
}

\section{ABSTRACT}

The aim of this study was to systematically evaluate the association between D-dimer level and the risk of stroke through performing a meta-analysis. PubMed, Web of Science, EMBASE and Cochrane Library were searched for potentially eligible literature. Prospective observational studies or case-control studies were included. The study characteristics and relevant data were extracted. Hazard ratios (HRs) or odds ratios (ORs) with $95 \%$ confidence intervals (CIs) were pooled to estimate the association between D-dimer level and the risk of stroke. Seven prospective studies with 22,207 patients and three case-control studies with 2,248 patients were included. For the prospective studies, the pooled HRs of higher D-dimer level for all types of stroke, ischemic stroke and hemorrhagic stroke were 1.55 (95\% CI, 1.28$1.87), 1.62$ (95\% CI, 1.18-2.22) and 1.30 (95\% CI, 0.63-2.68), respectively. The pooled HRs per SD increase in log D-dimer for all types of stroke, ischemic stroke and hemorrhagic stroke were 1.16 (95\% CI, 1.06-1.26), 1.11 (95\% CI, 1.03-1.21) and 1.11 (95\% CI, 0.95-1.30), respectively. For the case-control studies, the pooled OR of higher D-dimer level for acute ischemic stroke was 2.06 (95\% CI, 1.08-3.96). No significant publication bias was found in the meta-analysis. In conclusion, our results suggested that higher $\mathrm{D}$-dimer level was associated with higher risk of stroke, especially ischemic stroke.

\section{INTRODUCTION}

Stroke is one of the leading causes of mortality and disability worldwide [1]. In China, stroke is the leading cause of mortality and adult disability, with the annual stroke mortality rate of approximately 157 per 100,000 people [2]. Besides, stroke has a considerable impact on healthcare expenditures [2]. Ischemic stroke, characterized by the disruption of cerebral blood flow, accounts for approximately $80 \%-85 \%$ of all strokes [3]. Timely thrombolytic therapy is an effective treatment for acute ischemic stroke, however, the therapeutic window is very narrow [4]. Intracerebral hemorrhage (ICH) represents approximately $10 \%$ to $20 \%$ of all strokes [5]. ICH is characterized by high rates of mortality and disability, and currently little effective therapeutic strategies are available [6]. Primary prevention of stroke is essential and mainly includes the control of risk factors and preventive antithrombotic treatments [7]. Apart from the well-documented and modifiable risk factors, such as, physical inactivity, hypertension, dyslipidemia, diabetes mellitus and cigarette smoking, it is worthwhile to detect new potentially modifiable risk factors and control them at an early stage [7-9].

D-dimer, a circulating peptide degradation product of cross-linked fibrin, is formed during activation of the coagulation system [10]. Higher levels of D-dimer indicate more systemic fibrin formation and a tendency for increased thrombosis [11]. It has been proposed as a marker of the state of coagulation and fibrinolytic systems [12]. There are numerous assays for D-dimer measurement 
[13]. Enzyme-linked immunosorbent assay (ELISA) could provide highly sensitive quantitative results and has been used as the reference method [14]. However, it is a time-consuming procedure [13]. Immunoturbidimetric assay is another measurement of plasma D-dimer, and has shown comparable sensitivity and specificity $[13,15]$. Immunoturbidometric assay has also shown acceptable interassay coefficient of variation [16-18].

In clinical use, measurement of D-dimer has become an essential element to exclude deep vein thrombosis and pulmonary embolism $[19,20]$. It is also used in the diagnosis and monitoring of coagulation activation in disseminated intravascular coagulation [11]. D-dimer is a predictive marker for cardiovascular disease. It has been suggested that elevated D-dimer level not only is a risk factor of coronary heart disease [21, 22], but also predicts worse outcome in cardiovascular diseases [23, 24]. In patients with stroke, increased D-dimer level was found to be associated with worse functional outcome $[9,25,26]$. Many researchers have also investigated the relationship between D-dimer level and the risk of stroke. Some concluded that higher D-dimer was associated with higher risk of stroke [10,27, 28], but some investigators did not reach such conclusions [29, 30]. For example, in a case-control study by Kaplan et al. [29], the authors found that D-dimer was not an independent predictor of ischemic stroke. In a prospective study, in which the subjects were followed for a mean of 17 years, the researchers concluded that the predictive ability of D-dimer was modest and clinical utility remained uncertain [30]. Due to the controversy, a meta-analysis was designed to systematically review the association between D-dimer level and the risk of stroke, and to pool the evidence together to reach a conclusion.

\section{RESULTS}

\section{Literature research}

The initial database searching identified 2245 studies. No additional studies were identified through other sources. After removing duplicates, 1740 studies were screened by titles and abstracts. According to the predefined inclusion and exclusion criteria, 1691 studies were excluded. The rest 49 studies were evaluated in full text and 37 were further excluded due to unrelated, lacking enough data or other reasons. Two articles were from the same study cohort $[28,30]$, and the study with shorter follow-up time was excluded [28]. Another two articles were also from the same study cohort $[29,31]$, and the study with smaller sample size was excluded [31]. Eventually, 10 articles [10, 16-18, 29, 30, 32-35] met the inclusion criteria and were included. Of note, although two studies were from the same study cohort $[10,16]$, one study examined the risk of all types of stroke and the other examined the risk of intracerebral hemorrhage, so they were not pooled together during the analysis and were both included. The study selection process was shown in Figure 1.

\section{Study characteristics}

The basic characteristics of the 10 included studies were shown in Table 1. Among them, seven were from prospective studies. The seven prospective studies were published from 2005 to 2017, with 3 from UK, 3 from USA and 1 from Italy. A total of 22,207 patients were included (mean 3,172, median 1,750). The seven studies examined the HR of higher D-dimer level for all types of stroke, ischemic stroke or hemorrhagic stroke. All the HRs were calculated form multivariate analyses.

The rest three studies were case-control studies. They were published from 2007 to 2014, and were from 3 countries. A total of 2,248 patients were included (mean 749). All the three studies examined the OR of higher D-dimer level for acute ischemic stroke. The ORs were adjusted in two studies, while in the other study it is unclear whether the OR was adjusted or not.

\section{Pooled HR in prospective studies}

Five studies examined the HR of higher D-dimer level for all types of stroke [10, 17, 18, 30, 33]. The pooled HR of the five studies was 1.55 (95\% CI, 1.281.87) (Figure 2), suggesting that higher D-dimer level was associated with higher risk of stroke. No significant between-study heterogeneity was found $\left(\mathrm{I}^{2}=13.6 \%\right.$, $\mathrm{p}=0.327)$. Three of the five studies also examined the HR of all types of stroke per SD increase in log D-dimer $[17,18,33]$. The pooled HR of the three studies was 1.16 (95\% CI, 1.06-1.26). No significant between-study heterogeneity was found $\left(\mathrm{I}^{2}=34.6 \%, \mathrm{p}=0.217\right)$. Subgroup analysis results were shown in Table 2. All the HRs in the subgroups were statistically significant.

Three studies examined the HR of higher D-dimer level for ischemic stroke $[17,18,35]$. The pooled HR of the three studies was 1.62 (95\% CI, 1.18-2.22) (Figure 2), suggesting that higher D-dimer level was associated with higher risk of ischemic stroke. No significant betweenstudy heterogeneity was found $\left(\mathrm{I}^{2}=34.7 \%, \mathrm{p}=0.216\right)$. The subgroup analyses were shown in Table 2 and all the HRs in the subgroups were statistically significant. Two of the three studies also examined the HR of ischemic stroke per SD increase in log D-dimer [17, 18]. The pooled HR of the two studies was 1.11 (95\% CI, 1.03-1.21). No significant between-study heterogeneity was found $\left(\mathrm{I}^{2}=\right.$ $3.9 \%, \mathrm{p}=0.308$ ).

Three studies examined the HR of higher D-dimer level for hemorrhagic stroke [16-18]. The pooled HR of the three studies was 1.30 (95\% CI, 0.63-2.68) (Figure 2 ), suggesting no significant association between higher D-dimer level and the risk of hemorrhagic stroke. 
Significant heterogeneity was found between the studies $\left(\mathrm{I}^{2}=63.2 \%, \mathrm{p}=0.066\right)$. Sensitivity analysis revealed that the study by Di Castelnuovo et al. [18] contributed greatly to the heterogeneity. After removing this study, the heterogeneity turned to $12.3 \%$ however the pooled HR remained not statistically significant (HR 0.97; 95\% CI, 0.57-1.64). The three studies also examined the HR of hemorrhagic stroke per SD increase in log D-dimer, with the pooled HR of 1.11 (95\% CI, 0.95-1.30). No significant between-study heterogeneity was found $\left(\mathrm{I}^{2}=\right.$ $0.0 \%, p=0.525)$. The subgroup analyses were shown in Table 2. Most of the HRs in the subgroups were still not statistically significant.

\section{Pooled OR in case-control studies}

Three studies examined the OR of higher D-dimer level for acute ischemic stroke [29, 32, 34]. The pooled OR of the three studies was 2.06 (95\% CI, 1.08-3.96) (Figure 3), suggesting that higher D-dimer level was associated with higher risk of acute ischemic stroke. Significant heterogeneity was found between the studies $\left(\mathrm{I}^{2}=68.3 \%, \mathrm{p}=0.043\right)$. Sensitivity analysis revealed that the study by Kaplan et al. [29] contributed greatly to the heterogeneity. After removing this study, the heterogeneity turned to $0.0 \%$ and the pooled OR remained statistically significant (OR 2.86; 95\% CI, 1.635.03). The subgroup analyses were shown in Table 2.

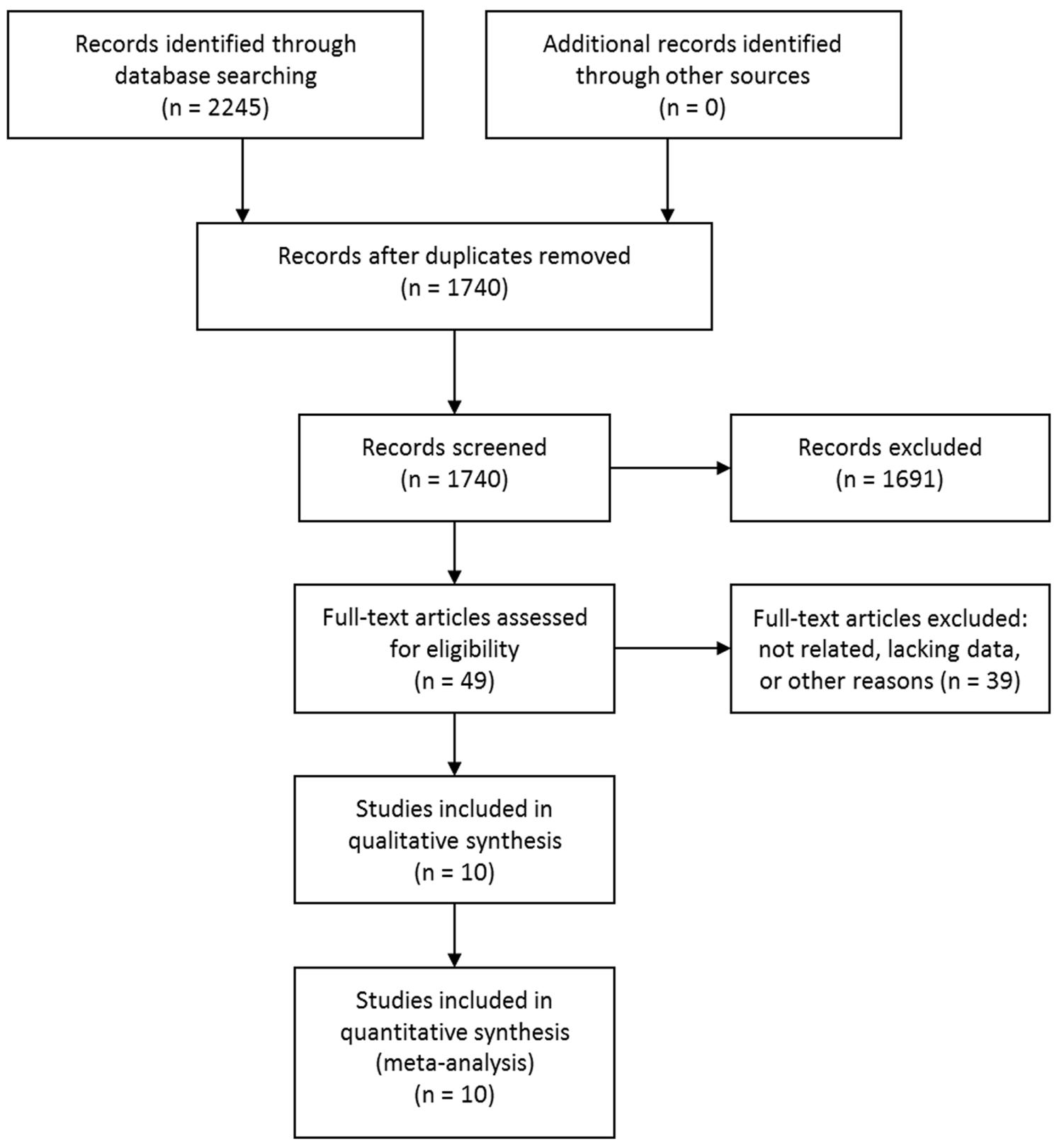

Figure 1: Selection process of studies. 
Table 1: Characteristics of the included studies

\begin{tabular}{|c|c|c|c|c|c|c|c|c|c|c|c|}
\hline Author & Year & Country & $\mathbf{N}(\mathbf{F} / \mathbf{M})$ & $\begin{array}{c}\text { Mean } \\
\text { age }\end{array}$ & Study & Disease & $\begin{array}{l}\text { Follow- } \\
\text { up time }\end{array}$ & $\begin{array}{l}\text { Measure } \\
\text { methods }\end{array}$ & $\begin{array}{l}\text { Cut-off } \\
\text { value }\end{array}$ & Estimate & $\begin{array}{c}\text { Adjusted } \\
\text { HR/OR }\end{array}$ \\
\hline \multicolumn{12}{|c|}{ Prospective studies } \\
\hline Tzoulaki & 2007 & UK & $1592(783 / 809)$ & 64.9 & The Edinburgh Artery Study & Stroke & $\begin{array}{l}\text { mean } \\
17 \mathrm{yrs}\end{array}$ & ELISA & tertile & $\mathrm{HR}$ & Yes \\
\hline Wannamethee & 2012 & UK & $3358(0 / 3358)$ & 68.4 & The British Regional Heart Study & Stroke & $\begin{array}{l}\text { mean } \\
9 \text { yrs }\end{array}$ & ELISA & $\begin{array}{l}\text { tertile/per } \\
\text { SD }\end{array}$ & HR & Yes \\
\hline Zakai & 2017 & USA & $1750(-/ 一)$ & - & The REGARDS Study & Stroke & $\begin{array}{c}\text { median } \\
5.8 \text { yrs }\end{array}$ & ITA & quintile & $\mathrm{HR}$ & Yes \\
\hline $\begin{array}{l}\text { Di } \\
\text { Castelnuovo }\end{array}$ & 2014 & Italy & $832(550 / 282)$ & - & The EPICOR Study & $\begin{array}{l}\text { Stroke/ } \\
\text { HS/IS }\end{array}$ & $\begin{array}{l}\text { mean } \\
9 \text { yrs }\end{array}$ & ITA & $\begin{array}{l}\text { quartile/ } \\
\text { per SD }\end{array}$ & HR & Yes \\
\hline Folsom & 2016 & USA & $\begin{array}{c}11415 \\
(6632 / 4783)\end{array}$ & 59.8 & The ARIC Study & $\begin{array}{c}\text { Stroke/ } \\
\text { HS/IS }\end{array}$ & $\begin{array}{c}\text { median } \\
18 \text { yrs }\end{array}$ & ITA & $\begin{array}{l}\text { quintile/ } \\
\text { per SD }\end{array}$ & $\mathrm{HR}$ & Yes \\
\hline Smith & 2005 & UK & $2208(0 / 2208)$ & 56.9 & The Caerphilly Study & IS & $\begin{array}{c}\text { median } \\
13 \text { yrs }\end{array}$ & ELISA & tertile & $\mathrm{HR}$ & Yes \\
\hline Zakai-2 & 2017 & USA & $1052(530 / 522)$ & 65.1 & The REGARDS Study & HS & $\begin{array}{c}\text { median } \\
5.8 \mathrm{yrs}\end{array}$ & ITA & $\begin{array}{l}\text { tertile/per } \\
\text { SD }\end{array}$ & HR & Yes \\
\hline \multicolumn{12}{|c|}{ Case-control studies } \\
\hline Anzej & 2007 & Slovenia & $90(55 / 35)$ & 38.5 & - & AIS & - & ITA & - & OR & NR \\
\hline Kaplan & 2008 & USA & $1944(1944 / 0)$ & - & The WHI observational study & AIS & - & ITA & - & OR & Yes \\
\hline Shi & 2014 & China & $214(90 / 124)$ & 67.4 & - & AIS & - & ITA & quartile & OR & Yes \\
\hline
\end{tabular}

N (F/M): number of patients (Female/Male), The REGARDS Study: The REasons for Geographic and Racial Differences in Stroke Study, The EPICOR Study: The European Prospective Investigation into Cancer and Nutrition-Italy Cohort Study, The ARIC Study: The Atherosclerosis Risk in Communities Study, The WHI observational study: The Women's Health Initiative observational study, HS: hemorrhagic stroke, IS: ischemic stroke, AIS: acute ischemic stroke, yrs: years, ELISA: enzyme-linked immunosorbent assay, ITA: immunoturbidimetric assay, SD: standard deviation, HR: hazard ratio, OR: odds ratio, NR: not reported.

\section{Publication bias}

No significant publication bias was found in the meta-analysis. The Begg's plot of publication bias of the 5 studies (examining the HR of higher D-dimer level for all types of stroke) was shown in Figure $4(\mathrm{p}=0.462)$.

\section{DISCUSSION}

This study aimed to evaluate the association between D-dimer level and the risk of stroke. We performed a meta-analysis to summarize the existing evidence, and ten studies were included. To our best knowledge, this is the first meta-analysis on this issue. After pooling the prospective and case-control studies, we found that higher D-dimer level was associated with higher risk of stroke, especially ischemic stroke. As to hemorrhagic stroke, our results suggested that D-dimer was not a risk factor. In the study by Folsom et al. [17], 11,415 participants were followed up for over a median of 18 years, and the authors also concluded that $\mathrm{D}$-dimer was not a risk factor for hemorrhagic stroke. But in another prospective study, the researchers suggested that elevated levels of D-dimers increase both the risk of ischaemic and hemorrhagic stroke [18]. In the study by Zakai et al, at first they found that D-dimer level was not significantly associated with hemorrhagic stroke modelled as a continuous variable or as tertiles [16]. They then added categories for the top and bottom $5 \%$ of the distribution and found a relationship with a potential threshold effect with increased risk of hemorrhagic stroke. Thus, given the different categories in the above-mentioned studies [17, 18] (quintiles and quartiles), D-dimer may be proposed as a risk factor in hemorrhagic stroke at a particular cut-off value in the future. Also, the number of studies focusing on hemorrhagic stroke is small. Therefore, more studies are needed to further explore this relationship.

Subgroup analyses were also performed according to the different characteristics of the studies. For the prospective studies, in the subgroups of all types of stroke and ischemic stroke, the HRs stayed significant, implying that D-dimer was a risk factor across different ethnicities, genders, D-dimer measurement methods and cut-off values of D-dimer. In the subgroups of hemorrhagic stroke, the HRs remained not statistically significant. For the case-control studies, the results differed across different ethnicities and genders. However, the number of studies in each subgroup was limited, and caution should be applied. More studies are warranted to verify these findings.

The underlining mechanism for the association between D-dimer level and the risk of stroke is unclear. A possible mechanism might be that D-dimer level could be a marker of systemic hypercoagulability that lead to ischemic stroke, since it may reflect the ongoing 
subclinical fibrin thrombus formation [36]. Folsom et al. found that higher plasma D-dimer was a risk marker for ischemic stroke, and that D-dimer is associated most strongly with cardioembolic stroke [17]. Their findings may support the above mechanism, since cardioembolic stroke is the subtype most closely linked to fibrin thrombi. D-dimer level may also reflect currently unclear thrombotic and haemostatic disorders that are related to stroke [18]. Besides, D-dimer level may reflect the heritability of the prethrombotic state [37]. Moreover, increased D-dimer may not be the causation, but a marker of a mechanism that is linked to the risk of stroke [18]. More studies are needed to elucidate the pathophysiology of such an association.

Our findings have some impact on future clinical and research work. First and foremost, D-dimer may help to screen patients at risk of stroke. Secondly, D-dimer may be used for clinical diagnosis of stroke. Besides, it may offer insights into future primary prevention strategies for stroke. Furthermore, it may be worthwhile to study

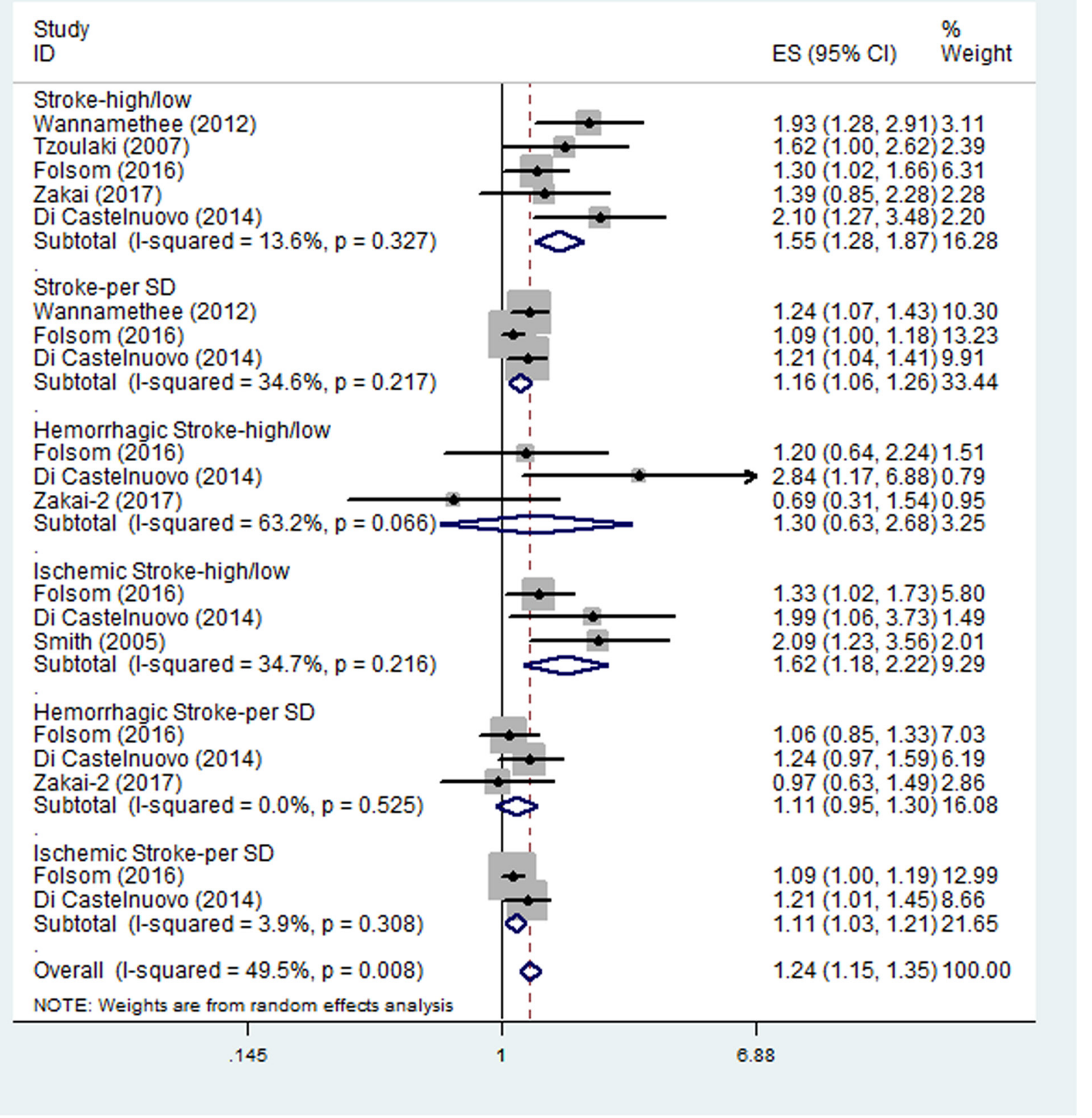

Figure 2: Pooled hazard ratios (HRs) of higher D-dimer level or per SD increase in log D-dimer for all types of stroke, ischemic stroke and hemorrhagic stroke. 
Table 2: Summary of meta-analysis results

\begin{tabular}{|c|c|c|c|c|c|c|}
\hline Prospective studies & $\begin{array}{c}\mathbf{N} \text { of } \\
\text { studies }\end{array}$ & $\begin{array}{c}\text { Pooled HR } \\
(95 \% \mathrm{CI})\end{array}$ & p value & $\begin{array}{c}\text { Heterogeneity } \\
\left(\mathrm{I}^{2}, \mathrm{P}\right)\end{array}$ & Conclusion & $\begin{array}{c}\text { Publication } \\
\text { bias }\end{array}$ \\
\hline \multicolumn{7}{|l|}{ Stroke-high/low } \\
\hline Total & 5 & $1.55(1.28-1.87)$ & $<0.001$ & $13.6 \%, 0.327$ & positive & 0.462 \\
\hline Ethnicity (Europe-white) & 3 & $1.87(1.44-2.44)$ & $<0.001$ & $0.0 \%, 0.752$ & positive & - \\
\hline Ethnicity (USA-with black) & 2 & $1.32(1.06-1.64)$ & 0.014 & $0.0 \%, 0.812$ & positive & - \\
\hline $\operatorname{Sex}(F / M>1)$ & 3 & $1.47(1.12-1.91)$ & 0.005 & $29.0 \%, 0.245$ & positive & - \\
\hline $\operatorname{Sex}(F / M<1)$ & 2 & $1.79(1.31-2.45)$ & $<0.001$ & $0.0 \%, 0.586$ & positive & - \\
\hline Sex (male) & 1 & $1.93(1.28-2.90)$ & - & - & positive & - \\
\hline Measurement (ITA) & 3 & $1.47(1.12-1.91)$ & 0.005 & $29.0 \%, 0.245$ & positive & - \\
\hline Measurement (ELISA) & 2 & $1.79(1.31-2.45)$ & $<0.001$ & $0.0 \%, 0.586$ & positive & - \\
\hline Cut-off (top quintile vs bottom) & 2 & $1.32(1.06-1.64)$ & 0.014 & $0.0 \%, 0.812$ & positive & - \\
\hline Cut-off (top quartile vs bottom) & 1 & $2.10(1.27-3.48)$ & - & - & positive & - \\
\hline Cut-off (top tertile vs bottom) & 2 & $1.79(1.31-2.45)$ & $<0.001$ & $0.0 \%, 0.586$ & positive & - \\
\hline \multicolumn{7}{|l|}{ Stroke-per SD } \\
\hline Total & 3 & $1.16(1.06-1.26)$ & 0.001 & $34.6 \%, 0.217$ & positive & 1 \\
\hline Ethnicity (Europe-white) & 2 & $1.23(1.10-1.36)$ & $<0.001$ & $0.0 \%, 0.819$ & positive & - \\
\hline Ethnicity (USA-with black) & 1 & $1.09(1.00-1.18)$ & - & - & positive & - \\
\hline $\operatorname{Sex}(F / M>1)$ & 2 & $1.13(1.02-1.24)$ & 0.014 & $28.8 \%, 0.236$ & positive & - \\
\hline Sex (male) & 1 & $1.24(1.08-1.44)$ & - & - & positive & - \\
\hline Measurement (ITA) & 2 & $1.13(1.02-1.24)$ & 0.014 & $28.8 \%, 0.236$ & positive & - \\
\hline Measurement (ELISA) & 1 & $1.24(1.08-1.44)$ & - & - & positive & - \\
\hline \multicolumn{7}{|l|}{ Ischemic Stroke-high/low } \\
\hline Total & 3 & $1.62(1.18-2.22)$ & 0.003 & $34.7 \%, 0.216$ & positive & 1 \\
\hline Ethnicity (Europe-white) & 2 & $2.05(1.37-3.07)$ & 0.001 & $0.0 \%, 0.907$ & positive & - \\
\hline Ethnicity (USA-with black) & 1 & $1.33(1.02-1.73)$ & - & - & positive & - \\
\hline $\operatorname{Sex}(F / M>1)$ & 2 & $1.46(1.05-2.05)$ & 0.026 & $25.4 \%, 0.247$ & positive & - \\
\hline Sex (male) & 1 & $2.09(1.23-3.56)$ & - & - & positive & - \\
\hline Measurement (ITA) & 2 & $1.46(1.05-2.05)$ & 0.026 & $25.4 \%, 0.247$ & positive & - \\
\hline Measurement (ELISA) & 1 & $2.09(1.23-3.56)$ & - & - & positive & - \\
\hline \multicolumn{7}{|l|}{ Ischemic Stroke-per SD } \\
\hline Total & 2 & $1.11(1.03-1.21)$ & 0.01 & $3.9 \%, 0.308$ & positive & 1 \\
\hline \multicolumn{7}{|l|}{ Hemorrhagic Stroke-high/low } \\
\hline Total & 3 & $1.30(0.63-2.68)$ & 0.484 & $63.2 \%, 0.066$ & negative & 1 \\
\hline Ethnicity (Europe-white) & 1 & $2.84(1.17-6.87)$ & - & - & positive & - \\
\hline Ethnicity (USA-with black) & 2 & $0.97(0.57-1.64)$ & 0.897 & $12.3 \%, 0.286$ & negative & - \\
\hline $\operatorname{Sex}(F / M>1)$ & 3 & $1.30(0.63-2.68)$ & 0.484 & $63.2 \%, 0.066$ & negative & - \\
\hline \multirow[t]{2}{*}{ Measurement (ITA) } & 3 & $1.30(0.63-2.68)$ & 0.484 & $63.2 \%, 0.066$ & negative & - \\
\hline & & & & & & (Continued) \\
\hline
\end{tabular}




\begin{tabular}{|c|c|c|c|c|c|c|}
\hline \multicolumn{7}{|l|}{ Hemorrhagic Stroke-per SD } \\
\hline Total & 3 & $1.11(0.95-1.30)$ & 0.177 & $0.0 \%, 0.525$ & negative & 1 \\
\hline Ethnicity (Europe-white) & 1 & $1.24(1.00-1.65)$ & - & - & positive & - \\
\hline Ethnicity (USA-with black) & 2 & $1.04(0.85-1.27)$ & 0.698 & $0.0 \%, 0.72$ & negative & - \\
\hline $\operatorname{Sex}(F / M>1)$ & 3 & $1.11(0.95-1.30)$ & 0.177 & $0.0 \%, 0.525$ & negative & - \\
\hline Measurement (ITA) & 3 & $1.11(0.95-1.30)$ & 0.177 & $0.0 \%, 0.525$ & negative & - \\
\hline Case control studies & $\begin{array}{c}\mathrm{N} \text { of } \\
\text { studies }\end{array}$ & $\begin{array}{l}\text { Pooled HR } \\
\text { (95\% CI) }\end{array}$ & p value & $\begin{array}{l}\text { Heterogeneity } \\
\left(\mathbf{I}^{2}, \mathbf{P}\right)\end{array}$ & Conclusion & $\begin{array}{c}\text { Publication } \\
\text { bias }\end{array}$ \\
\hline Total & 3 & $2.06(1.08-3.96)$ & 0.029 & $68.3 \%, 0.043$ & positive & 0.296 \\
\hline Western countries & 2 & $2.08(0.72-6.04)$ & 0.178 & $80.5 \%, 0.023$ & negative & - \\
\hline China & 1 & $2.32(1.12-4.81)$ & - & - & positive & - \\
\hline Sex (mixed) & 2 & $2.86(1.63-5.03)$ & $<0.001$ & $0.0 \%, 0.376$ & positive & - \\
\hline Sex (male) & 1 & $1.30(0.92-1.83)$ & - & - & negative & - \\
\hline Measurement (ITA) & 3 & $2.06(1.08-3.96)$ & 0.029 & $68.3 \%, 0.043$ & positive & - \\
\hline
\end{tabular}

$\mathrm{N}$ number, HR hazard ratio, CI confidence interval, OR odds ratio, $\mathrm{F} / \mathrm{M}>1$ female/male $>1, \mathrm{~F} / \mathrm{M}<1$ female/male $<1$, ITA immunoturbidimetric assay, ELISA enzyme-linked immunosorbent assay, SD standard deviation.

the benefit of lowering levels of D-dimer in high risk populations. Also, it may help to identify patients that could benefit more from agents targeted at haemostasis rather than platelet function.

Apart from its role as a risk factor of stroke, D-dimer could also be used in other aspects among stroke patients. Recent studies have shown that D-dimer levels were different in different subtypes of acute ischemic stroke [38, 39]. Its level is the highest in cardio-embolic stroke and lowest in lacunar subtype [39]. Many studies have demonstrated that, in patients with acute ischemic stroke, higher level of D-dimer was associated with higher risk of shortterm diffusion weighted-MRI defined recurrence [39], poorer functional outcome $[9,40]$, and higher risk of short-term mortality [41]. In patients with hemorrhagic stroke, higher level of D-dimer was also identified to predict poorer functional outcome and higher risk of short-term mortality [42, 43]. Besides, in patients with traumatic brain injury, antifibrinolytic treatment could reduce progressive hemorrhagic injury and improve outcomes [44, 45]. Thus, D-dimer may help explore new therapeutic targets for stroke in the future. Therefore, $\mathrm{D}$-dimer is a promising marker which may be used in the primary prevention, diagnosis, treatment and prognosis for stroke patients. Furthermore, D-dimer is readily accessible and inexpensive for measurement.

Significant between-study heterogeneity was present among the studies examining the HR of higher D-dimer level for hemorrhagic stroke and the studies examining the OR of higher D-dimer level for acute ischemic stroke. Sensitivity analyses were performed and identified the individual studies that contributed greatly to the heterogeneities. After removing the studies, the heterogeneities turned non-significant and the pooled results remained almost the same. Potential sources of heterogeneity may be from different patient races, sex distinction, different follow-up time, different measurement methods of D-dimer and different cut-off values of $\mathrm{D}$-dimer.

One of the strengths of this meta-analysis is that it included the latest large prospective studies. However, it still suffers from several limitations. Firstly, the metaanalysis was based on a small number of studies, so the results should be interpreted with caution. Secondly, the characteristics of the patients in each study were not all the same, such as different sex compositions, different follow-up time, and different cut-off values of D-dimer. Furthermore, significant between-study heterogeneity was present in some settings. Although random effect models were used to minimize the effects on results, more studies are still needed to verify these findings. Besides, although no significant publication bias was found in our metaanalysis, it was a major concern for all meta-analyses and should not be completely excluded.

In conclusion, our results suggested that higher D-dimer level was associated with higher risk of stroke, especially ischemic stroke. As a readily accessible and inexpensive marker, D-dimer is promising in the primary prevention for stroke. However, due to the limited number of studies, more studies are warranted to further verify our results. 
Overall $(\mathrm{I}$-squared $=68.3 \%, \mathrm{p}=0.043$ )

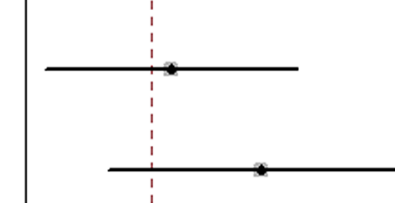

NOTE: Weights are from random effects analysis

Figure 3: Pooled odds ratio (OR) of higher D-dimer level for acute ischemic stroke.

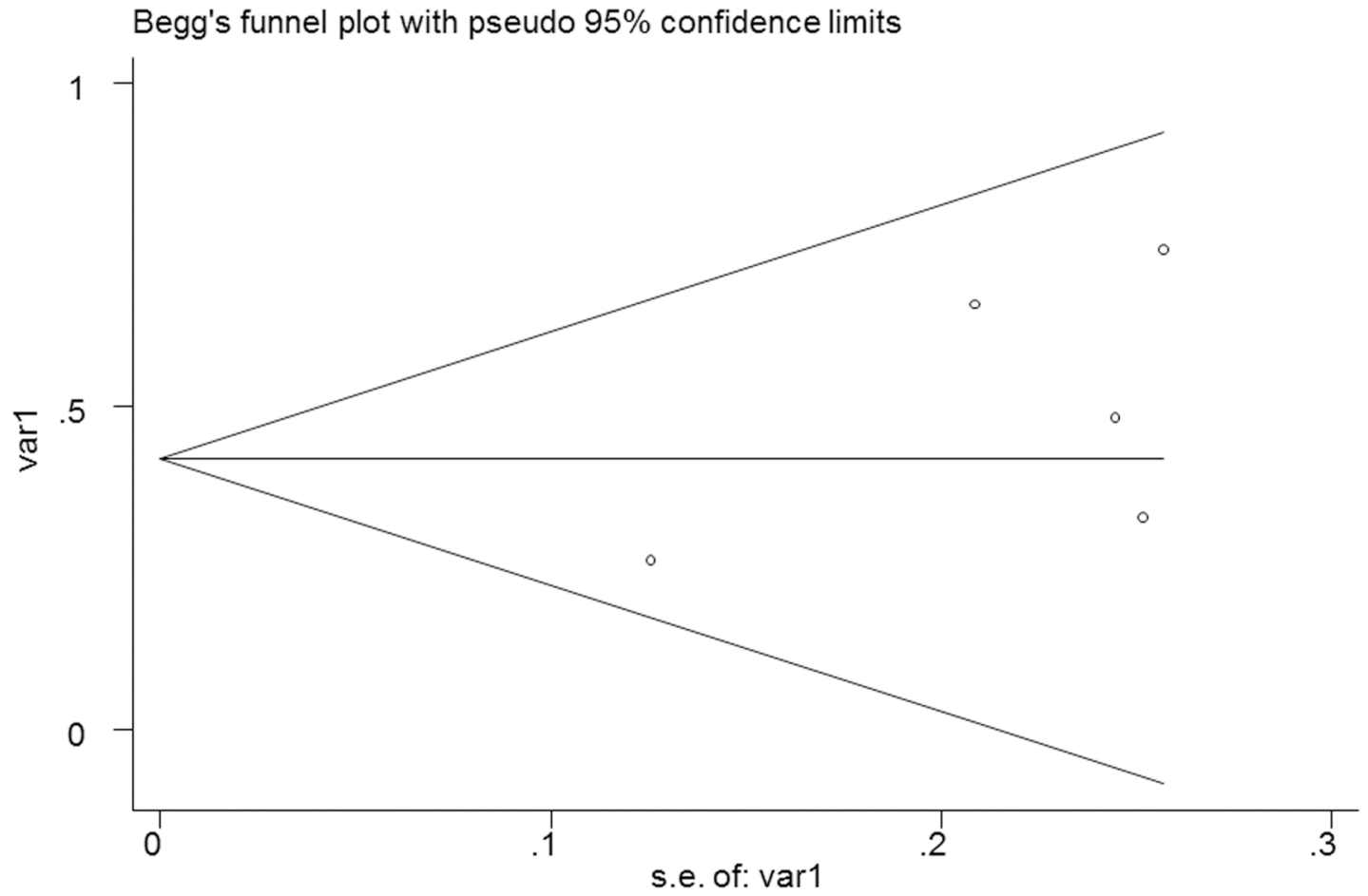

Figure 4: The Begg's publication bias plot of the 5 studies examining the HR of higher D-dimer level for all types of stroke $(p=0.462)$. 


\section{MATERIALS AND METHODS}

\section{Search strategy}

We followed the developed guidelines for systematic reviews and meta-analyses in performing our study [46]. PubMed, Web of Science, EMBASE and Cochrane Library were searched for potentially eligible literature (last update on Aug 2ed, 2017). The following keywords were used: 'D-dimer' AND ('Stroke' OR 'Brain Ischemia' OR 'Brain Infarction' OR 'Cerebral Infarction' OR 'Intracranial Hemorrhage' OR 'Cerebral Hemorrhage') AND ('Risk' OR 'Risk Factors' OR 'Relative Risk' OR 'Odds Ratio'. Reference lists of relevant studies were also screened for additional literature. Languages were restricted to English and Chinese.

\section{Study selection}

The study selection process was performed by two reviewers (JZ and YS) independently, with any disagreements being discussed. Titles and abstracts of literature were screened first, and then potentially eligible studies were evaluated in full text. Studies were considered for inclusion if they met all of the following criteria: (1) prospective observational studies or case-control studies; (2) blood samples were collected at baseline or after admission to assess the level of D-dimer; (3) for prospective observational studies, patients were followed up for stroke events (either ischemic or hemorrhagic); for case-control studies, stroke patients were compared with controls; (4) enough data was reported to estimate the association between D-dimer level and the risk of stroke. Letters, case reports, reviews, conference abstracts, unrelated articles, and studies without enough data were excluded. If multiple studies were performed in the same center and the patients overlapped, the study with the largest sample size and longest follow-up time was included.

\section{Data extraction}

Relevant data were extracted from the eligible studies by two researchers (JZ and YS) independently, and disagreements were resolved by consensus. The primary data was hazard ratio (HR) or odds ratio (OR) with $95 \%$ confidence interval (CI), or the data that could be used to calculate the HR or OR with $95 \%$ CI. Estimates calculated form multivariate analyses were extracted over those calculated from univariate analyses. The characteristics of the studies and patients were also extracted, including first author, publication year, country, study design, follow-up time, patients' number, sex of patients, mean or median age of patients and so on.

\section{Statistical analysis}

The $\log \mathrm{HR}$ (or $\log \mathrm{OR}$ ) and variance were calculated from the HR (or OR) and 95\% CI, and were used for aggregation of data. Forest plots were constructed to estimate the association between D-dimer level and the risk of stroke. The pooled HR (or OR) was regarded significant if the $\mathrm{p}$ value was less than 0.05 and the $95 \%$ CI did not overlap 1. Subgroup analyses were also performed according to patient ethnicity, gender, D-dimer measurement method and cut-off value of D-dimer. The heterogeneity between studies was also assessed, with $\mathrm{I}^{2}>50 \%$ or $\mathrm{p}<0.10$ indicating significant heterogeneity [47]. Random effect models were used in pooling the studies no matter whether heterogeneity exited, since some heterogeneity among studies was expected due to differences in patient characteristics, D-dimer level measuring and other study differences [48]. If heterogeneity was present, sensitivity analysis was performed to evaluate the contribution of each study to heterogeneity by excluding individual studies one at a time. Publication bias was assessed by Begg's test, with $\mathrm{p}>0.05$ indicating no significant publication bias. All the above mentioned statistical analyses were performed by STATA 11.0 (STATA Corporation, College Station, TX).

\section{ACKNOWLEDGMENTS}

We would like to thank the reviewers for their constructive comments.

\section{CONFLICTS OF INTEREST}

The authors declare no conflicts of interests.

\section{FUNDING}

National Key Technology Research and Development Program of the Ministry of Science and Technology of China; The National Brain Tumor Registry of China (NBTRC) (The Key Control Technology Research for Ischemic Cerebrovascular Disease and Brain Tumor, 2015BAI12B04).

\section{REFERENCES}

1. Johnston SC, Mendis S, Mathers CD. Global variation in stroke burden and mortality: estimates from monitoring, surveillance, and modelling. Lancet Neurol. 2009; 8: $345-$ 54. https://doi.org/10.1016/S1474-4422(09)70023-7.

2. Liu L, Wang D, Wong KS, Wang Y. Stroke and stroke care in China: huge burden, significant workload, and a national priority. Stroke. 2011; 42: 3651-4. https://doi.org/10.1161/ STROKEAHA.111.635755. 
3. Allen CL, Bayraktutan U. Oxidative stress and its role in the pathogenesis of ischaemic stroke. Int J Stroke. 2009; 4: 461-70. https://doi.org/10.1111/j.1747-4949.2009.00387.x.

4. Park SY, Kim J, Kim OJ, Kim JK, Song J, Shin DA, Oh $\mathrm{SH}$. Predictive value of circulating interleukin-6 and hearttype fatty acid binding protein for three months clinical outcome in acute cerebral infarction: multiple blood markers profiling study. Crit Care. 2013; 17: R45. https:// doi.org/10.1186/cc12564.

5. Ikram MA, Wieberdink RG, Koudstaal PJ. International epidemiology of intracerebral hemorrhage. Curr Atheroscler Rep. 2012; 14: 300-6. https://doi.org/10.1007/ s11883-012-0252-1.

6. Hemphill JC 3rd, Greenberg SM, Anderson CS, Becker K, Bendok BR, Cushman M, Fung GL, Goldstein JN, Macdonald RL, Mitchell PH, Scott PA, Selim MH, Woo $\mathrm{D}$, et al. Guidelines for the management of spontaneous intracerebral hemorrhage: a guideline for healthcare professionals from the american heart association/American stroke association. Stroke. 2015; 46: 2032-60. https://doi. org/10.1161/STR.037262R1037262R10069.

7. Meschia JF, Bushnell C, Boden-Albala B, Braun LT, Bravata DM, Chaturvedi S, Creager MA, Eckel RH, Elkind MS, Fornage M, Goldstein LB, Greenberg SM, Horvath SE, et al. Guidelines for the primary prevention of stroke: a statement for healthcare professionals from the American Heart Association/American Stroke Association. Stroke. 2014; 45: 3754-832. https://doi.org/10.1161/ STR.037262R1037262R10046.

8. Xue J, Huang W, Chen X, Li Q, Cai Z, Yu T, Shao B. Neutrophil-to-Lymphocyte ratio is a prognostic marker in acute ischemic stroke. J Stroke Cerebrovasc Dis. 2017; 26: 650-7. https://doi.org/10.1016/j.jstrokecerebrovas dis.2016.11.010.

9. Wang J, Ning R, Wang Y. Plasma D-dimer level, the promising prognostic biomarker for the acute cerebral infarction patients. J Stroke Cerebrovasc Dis. 2016; 25: 2011-5. https://doi.org/10.1016/j.jstrokecerebrovas dis.2015.12.031.

10. Zakai NA, McClure LA, Judd SE, Kissela B, Howard G, Safford M, Cushman M. D-dimer and the Risk of Stroke and Coronary Heart Disease. The REasons for Geographic and Racial Differences in Stroke (REGARDS) Study. Thromb Haemost. 2017; 117: 618-24. https://doi. org/10.1160/th16-07-0519.

11. Adam SS, Key NS, Greenberg CS. D-dimer antigen: current concepts and future prospects. Blood. 2009; 113: 2878-87. https://doi.org/10.1182/blood-2008-06-165845.

12. Goldenberg NA, Jenkins S, Jack J, Armstrong-Wells J, Fenton LZ, Stence NV, Oleszek J, Boada R, Wilkening GN, Wilkinson C, Soep JB, Miyamoto SD, Bajaj L, et al. Arteriopathy, D-dimer, and risk of poor neurologic outcome in childhood-onset arterial ischemic stroke. J Pediatr. 2013; 162: 1041-6.e1. https://doi.org/10.1016/j.jpeds.2012.11.035.
13. Park SJ, Chi HS, Chun SH, Jang S, Park CJ. Evaluation of performance including influence by interfering substances of the Innovance D-dimer assay on the Sysmex coagulation analyzer. Ann Clin Lab Sci. 2011; 41: 20-4.

14. Stein PD, Hull RD, Patel KC, Olson RE, Ghali WA, Brant R, Biel RK, Bharadia V, Kalra NK. D-dimer for the exclusion of acute venous thrombosis and pulmonary embolism: a systematic review. Ann Intern Med. 2004; 140: 589-602.

15. Bozic M, Stegnar M. Validation of an automated immunoturbidimetric assay for measurement of plasma D-dimer. Clin Chem Lab Med. 2003; 41: 958-62. https:// doi.org/10.1515/CCLM.2003.146.

16. Zakai N, Olson NC, Judd SE, Kleindorfer DO, Kissela BM, Howard G, Cushman M. Haemostasis biomarkers and risk of intracerebral haemorrhage in the REasons for Geographic and Racial Differences in Stroke Study. Thromb Haemost. 2017; 117: 1808-15. https://doi.org/10.1160/TH17-03-0189.

17. Folsom AR, Gottesman RF, Appiah D, Shahar E, Mosley TH. Plasma d-Dimer and Incident ischemic stroke and coronary heart disease: the atherosclerosis risk in communities study. Stroke. 2016; 47: 18-23. https://doi. org/10.1161/strokeaha.115.011035.

18. Di Castelnuovo A, Agnoli C, de Curtis A, Giurdanella MC, Sieri S, Mattiello A, Matullo G, Panico S, Sacerdote C, Tumino R, Vineis P, de Gaetano G, Donati MB, et al. Elevated levels of D-dimers increase the risk of ischaemic and haemorrhagic stroke. Findings from the EPICOR Study. Thromb Haemost. 2014; 112: 941-6. https://doi. org/10.1160/th14-04-0297.

19. van der Hulle T, Cheung WY, Kooij S, Beenen LF, van Bemmel T, van Es J, Faber LM, Hazelaar GM, Heringhaus C, Hofstee H, Hovens MM, Kaasjager KA, van Klink $\mathrm{RC}$, et al. Simplified diagnostic management of suspected pulmonary embolism (the YEARS study): a prospective, multicentre, cohort study. Lancet. 2017; 390: 289-97. https://doi.org/10.1016/S0140-6736(17)30885-1.

20. Kraaijpoel N, van Es N, Porreca E, Buller HR, Di Nisio M. The diagnostic management of upper extremity deep vein thrombosis: a review of the literature. Thromb Res. 2017; 156: 54-9. https://doi.org/10.1016/j.thromres.2017.05.035.

21. Kleinegris MC, ten Cate H, ten Cate-Hoek AJ. D-dimer as a marker for cardiovascular and arterial thrombotic events in patients with peripheral arterial disease. a systematic review. Thromb Haemost. 2013; 110: 233-43. https://doi. org/10.1160/TH13-01-0032.

22. Danesh J, Whincup P, Walker M, Lennon L, Thomson A, Appleby P, Rumley A, Lowe GD. Fibrin D-dimer and coronary heart disease: prospective study and meta-analysis. Circulation. 2001; 103: 2323-7.

23. Huang B, Yang Y, Lu H, Zhao Z, Zhang S, Hui R, Fan X. Impact of d-Dimer levels on admission on inhospital and long-term outcome in patients with type a acute aortic dissection. Am J Cardiol. 2015; 115: 1595-600. https://doi. org/10.1016/j.amjcard.2015.02.067. 
24. Zorlu A, Yilmaz MB, Yucel H, Bektasoglu G, Refiker Ege M, Tandogan I. Increased d-dimer levels predict cardiovascular mortality in patients with systolic heart failure. J Thromb Thrombolysis. 2012; 33: 322-8. https:// doi.org/10.1007/s11239-011-0635-0.

25. Sienkiewicz-Jarosz H, Galecka-Wolska M, Bidzinski A, Turzynska D, Sobolewska A, Lipska B, Plaznik A, Ryglewicz D. Predictive value of selected biochemical markers of brain damage for functional outcome in ischaemic stroke patients. Neurol Neurochir Pol. 2009; 43: 126-33.

26. Fukuda H, Lo B, Yamamoto Y, Handa A, Yamamoto Y, Kurosaki Y, Yamagata S. Plasma D-dimer may predict poor functional outcomes through systemic complications after aneurysmal subarachnoid hemorrhage. J Neurosurg. 2016; 127: 1-7. https://doi.org/10.3171/2016.5.jns16767.

27. Landry KK, Alexander KS, Zakai NA, Judd SE, Kleindorfer DO, Howard VJ, Howard G, Cushman M. Association of stroke risk biomarkers with stroke symptoms: the reasons for geographic and racial differences in stroke cohort. J Thromb Haemost. 2017; 15: 21-7. https://doi.org/10.1111/ jth.13562.

28. Smith FB, Lee AJ, Fowkes FG, Price JF, Rumley A, Lowe GD. Hemostatic factors as predictors of ischemic heart disease and stroke in the Edinburgh Artery study. Arterioscler Thromb Vasc Biol. 1997; 17: 3321-5.

29. Kaplan RC, McGinn AP, Baird AE, Hendrix SL, Kooperberg C, Lynch J, Rosenbaum DM, Johnson KC, Strickler HD, Wassertheil-Smoller S. Inflammation and hemostasis biomarkers for predicting stroke in postmenopausal women: the Women's Health Initiative Observational Study. J Stroke Cerebrovasc Dis. 2008; 17: 344-55. https://doi. org/10.1016/j.jstrokecerebrovasdis.2008.04.006.

30. Tzoulaki I, Murray GD, Lee AJ, Rumley A, Lowe GD, Fowkes FG. Relative value of inflammatory, hemostatic, and rheological factors for incident myocardial infarction and stroke - The Edinburgh Artery Study. Circulation. 2007; 115: 2119-27. https://doi.org/10.1161/ circulationaha.106.635029.

31. Kooperberg C, Cushman M, Hsia J, Robinson JG, Aragaki AK, Lynch JK, Baird AE, Johnson KC, Kuller LH, Beresford SA, Rodriguez B. Can biomarkers identify women at increased stroke risk? The women's health initiative hormone trials. PLoS Clin Trials. 2007; 2: e28. https://doi.org/10.1371/journal.pctr.0020028.

32. Shi D, Xia T, Feng H, Cheng Q. Evaluating the diagnostic value of vWF:Ag, D-D and FDP in patients with acute cerebral infarction using ROC curves. Exp Ther Med. 2014; 7: 1573-7. https://doi.org/10.3892/etm.2014.1665.

33. Wannamethee SG, Whincup PH, Lennon L, Rumley A, Lowe GD. Fibrin D-dimer, tissue-type plasminogen activator, von Willebrand factor, and risk of incident stroke in older men. Stroke. 2012; 43: 1206-11. https://doi. org/10.1161/strokeaha.111.636373.
34. Anzej S, Bozic M, Antovic A, Peternel P, Gaspersic N, Rot U, Tratar G, Stegnar M. Evidence of hypercoagulability and inflammation in young patients long after acute cerebral ischaemia. Thromb Res. 2007; 120: 39-46. https://doi. org/10.1016/j.thromres.2006.08.005.

35. Smith A, Patterson C, Yarnell J, Rumley A, Ben-Shlomo Y, Lowe G. Which hemostatic markers add to the predictive value of conventional risk factors for coronary heart disease and ischemic stroke? The caerphilly study. Circulation. 2005; 112: 3080-7. https://doi.org/10.1161/ circulationaha.105.557132.

36. Barber M, Langhorne P, Rumley A, Lowe GD, Stott DJ. Hemostatic function and progressing ischemic stroke: D-dimer predicts early clinical progression. Stroke. 2004; 35: 1421-5. https://doi.org/10.1161/01. str.0000126890.63512.41.

37. Ariens RA, de Lange M, Snieder H, Boothby M, Spector TD, Grant PJ. Activation markers of coagulation and fibrinolysis in twins: heritability of the prethrombotic state. Lancet. 2002; 359: 667-71. https://doi.org/10.1016/ S0140-6736(02)07813-3.

38. Dougu N, Takashima S, Sasahara E, Taguchi Y, Toyoda S, Hirai T, Nozawa T, Tanaka K, Inoue H. Predictors of poor outcome in patients with acute cerebral infarction. J Clin Neurol. 2011; 7: 197-202. https://doi.org/10.3988/ jen.2011.7.4.197.

39. Abdel Ghani AA, Zaitoun AM, Gawish Ha H, Abo Warda MH. Prognostic value of D-dimer in diffusion weightedMRI defined early ischemic stroke recurrence. Egypt J Neurol Psychiat Neurosurg. 2011; 48: 215-22.

40. Welsh P, Barber M, Langhorne P, Rumley A, Lowe GD, Stott DJ. Associations of inflammatory and haemostatic biomarkers with poor outcome in acute ischaemic stroke. Cerebrovasc Dis. 2009; 27: 247-53. https://doi. org/10.1159/000196823.

41. Dieplinger B, Bocksrucker C, Egger M, Eggers C, Haltmayer M, Mueller T. Prognostic value of inflammatory and cardiovascular biomarkers for prediction of 90-day allcause mortality after acute ischemic stroke results from the linz stroke unit study. Clin Chem. 2017; 63: 1101-9. https:// doi.org/10.1373/clinchem.2016.269969.

42. Chiu CC, Li YN, Lin LJ, Hsiao CT, Hsiao KY, Chen IC. Serum D-dimer as a predictor of mortality in patients with acute spontaneous intracerebral hemorrhage. J Clin Neurosci. 2012; 19: 810-3. https://doi.org/10.1016/j. jocn.2011.08.032.

43. Siironen J, Porras M, Varis J, Poussa K, Hernesniemi J, Juvela S. Early ischemic lesion on computed tomography: predictor of poor outcome among survivors of aneurysmal subarachnoid hemorrhage. J Neurosurg. 2007; 107: 1074-9. https://doi.org/10.3171/jns-07/12/1074.

44. Crash-2 Collaborators Intracranial Bleeding Study. Effect of tranexamic acid in traumatic brain injury: a nested randomised, placebo controlled trial (CRASH-2 Intracranial 
Bleeding Study). BMJ. 2011; 343: d3795. https://doi. org/10.1136/bmj.d3795.

45. Roberts I, Shakur H, Afolabi A, Brohi K, Coats T, Dewan Y, Gando S, Guyatt G, Hunt BJ, Morales C, Perel P, Prieto-Merino D, Woolley T; CRASH-2 Collaborators. The importance of early treatment with tranexamic acid in bleeding trauma patients: an exploratory analysis of the CRASH-2 randomised controlled trial. Lancet. 2011; 377: 1096-101, 101 e1-2. https://doi.org/10.1016/ S0140-6736(11)60278-X.

46. Moher D, Shamseer L, Clarke M, Ghersi D, Liberati A, Petticrew M, Shekelle P, Stewart LA; PRISMA-P Group.
Preferred reporting items for systematic review and metaanalysis protocols (PRISMA-P) 2015 statement. Syst Rev. 2015; 4: 1. https://doi.org/10.1186/2046-4053-4-1.

47. Higgins JP, Thompson SG, Deeks JJ, Altman DG. Measuring inconsistency in meta-analyses. BMJ. 2003; 327: 557-60. https://doi.org/10.1136/bmj.327.7414.557.

48. Specogna AV, Turin TC, Patten SB, Hill MD. Factors associated with early deterioration after spontaneous intracerebral hemorrhage: a systematic review and meta-analysis. PLoS One. 2014; 9: e96743. https://doi. org/10.1371/journal.pone.0096743. 